CZASOPISMO INŻYNIERII LĄDOWEJ, ŚRODOWISKA I ARCHITEKTURY JOURNAL OF CIVIL ENGINEERING, ENVIRONMENT AND ARCHITECTURE JCEEA, t. XXXIII, z. 63 (3/16), lipiec-wrzesień 2016, s. 373-380

\author{
Adam RUSZAJ ${ }^{1}$
}

\title{
BIOINSPIRACJE W INŻYNIERII ŚRODOWISKA
}

\begin{abstract}
Żadna maszyna czy proces zaprojektowane przez inżynierów nie dorównują doskonałości organizmów żywych i procesów zachodzących w środowisku naturalnym, które stworzyła Natura w procesie ewolucji. Bardzo prężny rozwój technologii wymusza poszukiwanie nowych racjonalnych rozwiązań technicznych przyjaznych dla środowiska naturalnego. Dzięki temu może uda się zmniejszyć skutki „efektu cieplarnianego” czy „dziury ozonowej” oraz poprawić jakość powietrza, wody i żywności. Jednym z bardzo ważnych problemów środowiskowych jest produkcja energii i jej racjonalne wykorzystanie. Produkcja energii w Polsce oparta jest na spalaniu węgla, ropy gazowej oraz gazu ziemnego co wywiera niekorzystny wpływ na środowisko. Dlatego należy intensywnie rozwijać i udoskonalać produkcję ,,czystej energii”. Ponadto bardzo ważnym zagadnieniem jest racjonalne wykorzystanie energii zarówno w gospodarstwach indywidualnych (ocieplenie budynków, sprzęt AGD i RTV) jak i przy projektowaniu i eksploatacji wszystkich innych urządzeń: zaczynając od samolotów i samochodów przez maszyny rolnicze i budowlane do sprzętu komputerowego czy medycznego. Oszczędzać energię można również pośrednio przez zmniejszanie masy urządzeń oraz zwiększanie trwałości ich elementów. Skutkuje to oszczędnością materiałów a tym samym energii, która zostałaby zużyta na ich wyprodukowanie. Pomost pomiędzy rozwiązaniami spotykanymi w przyrodzie a techniką tworzy dziedzina nauki nazywana ,bioniką", która bada materiały, struktury, kształty i powierzchnie występujące w roślinach czy zwierzętach oraz ich wytwory (plaster miodu, kopiec termitrów) i zachowania społeczne (mrówki, ryby, muchy, pszczoły). Wyniki tych badań stanowią inspiracje w rozwiazywaniu zagadnień konstrukcyjnych, eksploatacyjnych, organizacyjnych, medycznych a nawet informatycznych. $W$ artykule przedstawiono wybrane zastosowania osiągnięć „,bioniki” w technice z punktu widzenia inżynierii środowiska ze szczególnym uwzględnieniem produkcji i zużycia energii.
\end{abstract}

Słowa kluczowe: bionika, konstrukcje lekkie, czysta energia, energooszczędne urządzenia, odporność na zużycie

\section{Wprowadzenie}

Rozwój naszej cywilizacji przez ostatnie kilka tysięcy lat był niezwykle dynamiczny ale nie naruszający równowagi w środowisku naturalnym. Ludzkość gospodarowała w wyznaczonych przez naturę granicach biosfery, nie było zagrożeń globalnych dla życia na kuli ziemskiej z wyjątkiem naturalnych zjawisk niezależ-

\footnotetext{
${ }^{1}$ Adam Ruszaj, Instytut Technologii Maszyn I Automatyzacji Produkcji Politechniki Krakowskiej; ruszaj@mech.pk.edu.pl
} 
nych od człowieka (wybuchy wulkanów, powodzie itp.) oraz wojen czy epidemii np. dżumy, czarnej ospy czy cholery. Sytuacja zmieniła się skokowo od momentu wynalezienia silnika parowego przez Thomasa Newcomena (1712 r. ), udoskonalonego przez James Watta w 1763 r., co zapoczątkowało pierwszą rewolucji przemysłową. Nastąpił gwałtowny wzrost produkcji przemysłowej i związane z tym zapotrzebowanie na energię. Energia była i jest głównie uzyskiwana przez spalanie węgla, ropy i gazu ziemnego. Związana z tym emisja zanieczyszczeń gazowych i pyłów do atmosfery, odprowadzanie, ścieków i odpadów stałych z zakładów przemysłowych i gospodarstw indywidualnych, powszechne stosowanie środków ochrony roślin znacząco zmieniły warunki funkcjonowania ekosystemów zarówno w skali lokalnej jak i globalnej (efekt cieplarniany, dziura ozonowa, kwaśnie deszcze). Oczywiście rozwoju gospodarczego nie można zatrzymać bo wymusza go wciąż rosnąca konsumpcja już 7 miliardów ludzi, z których każdy potrzebuje, pożywienia, ubrania, dobrze wyposażonego mieszkania, często samochodu, motoru, roweru itp. Ale muszą być podjęte radykalne działania, żeby ograniczyć wpływ rozwoju przemysłu czy komunikacji na stan środowiska naturalnego.

\section{Sformułowanie problemu}

Nawet pobieżna analiza stanu środowiska naturalnego wskazuje, że produkcja energii oparta na spalaniu węgla, ropy naftowej czy gazu w połączeniu z nieekonomicznym jej wykorzystaniem wywiera niekorzystny wpływ na środowisko naturalne. Należy zatem rozwijać produkcję energii czystej wykorzystując biomasę, energię słoneczną, energię rzek i oceanów czy energię wiatru. Ale równocześnie niezwykle ważne jest ograniczenie zużycia energii oraz ekonomiczne jej wykorzystanie. Oczywiście podejmowane są działania we wszystkich wymienionych powyżej obszarach, ale często najkorzystniejsze rozwiązania można znaleźć w organizmach żywych (rośliny, zwierzęta), które Natura wytworzyła w wyniku procesu ewolucji. Pomost pomiędzy światem roślin i zwierząt a techniką tworzy nauka nazywana bioniką. Nazwa „bionika” pochodzi od słów greckich: bios - życie oraz mimesis -naśladować. Poniżej przedstawiono przykłady racjonalnego wykorzystania bioinspiracji w aspekcie produkcji i racjonalnego wykorzystania energii.

\section{Charakterystyka kształtów, struktur i powierzchni występują- cych w naturze}

W większości rozwiązań technicznych zwykle stosowane są regularne kształty (walec, prostopadłościan, ostrosłup, stożek, kula itp.), regularne struktury (elementy prostoliniowe ułożone równomiernie i zwykle równolegle lub prostopadle) oraz gładkie powierzchnie. W organizmach żywych regularne kształty, struktury czy gładkie powierzchnie nie występują ponieważ nie są one optymalne ze względu na warunki w jakich organizmy żyją [1-6]. I tak kształt ciała kreta oraz jego łapy są przystosowane do życia pod ziemią i kopania korytarzy (Rys.1). Występu- 
jące $\mathrm{w}$ organizmach żywych struktury zadziwiają różnorodnością wynikającą z konieczności przystosowania organizmów do warunków życia. Najbardziej pospolite organizmy jak drzewa, krzewy, pędy bambusa mają optymalnie ukształtowane pod względem wytrzymałościowym korony oraz użyłkowanie liści. Również szkielety ptaków czy ssaków stanowią lekkie, funkcjonalne i wytrzymałe układy przestrzenne [7, 8]. Warto podkreślić, że szkielet gołębia waży tylko 8-9\% jego masy całkowitej [7]. Wynika to z faktu, że wewnętrzna struktura kości jest niejednorodna i z pustymi przestrzeniami. Analogicznie można scharakteryzować strukturę wewnętrzną roślin.

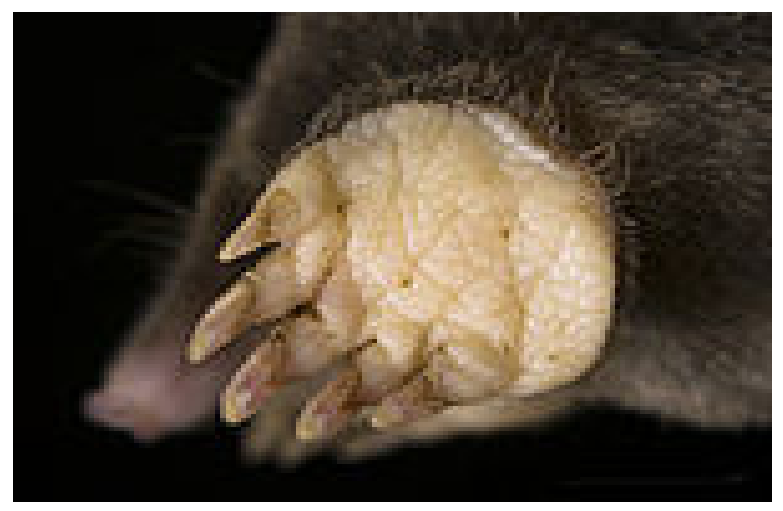

Rys.1. Przednia łapa kreta [1]

Fig.1. The fore paw of mole rat [1]

Specyficzną budowę wewnętrzną umożliwiającą tłumienie drgań posiadają dzioby ptaków (szczególnie tukana czy dzięcioła). Dzięki temu drgania generowane podczas uderzenia dziobem nie przenoszą się na cały organizm. W przyrodzie nie występują również tzw. ,gładkie” powierzchnie. Na przykład muszle skorupiaków mają charakterystyczne prążki, które istotnie zwiększają wytrzymałość i odporność na zużycie. Również żuk gnojowy (Rys.2) posiada zróżnicowaną strukturę skrzydeł, tułowia czy głowy. Zdjęcia zrobione skaningowym mikroskopem elektronowym (SME) wykazują, że skrzydła mają strukturę prążkową, w tułowiu znajdują się liczne wgłębienia i delikatne wypukłości. Żuk gnojowy przekopuje duże ilości nawozu i gleby oraz przemieszcza się sprawnie w glebie lub nawozie ponieważ dzięki niepłaskiej i zróżnicowanej strukturze powierzchni ciała minimalizuje opory ruchu. Wynika to z faktu, że pomiędzy glebę a ciało żuka dostaje się powietrze i woda powodując efekt smarowania a w konsekwencji zmniejszenie oporów ruchu.

Nawet tak delikatne narządy jak skóra czy skrzydła motyla nie są gładkie; posiadają one specyficzną łuskową i warstwową strukturę ukształtowaną w procesie ewolucji trwającym kilkaset milionów lat [3]. Warto podkreślić, że pierwsze owady latające w okresie Carbonu" miały powierzchnie skrzydeł gładkie i dlatego ich 


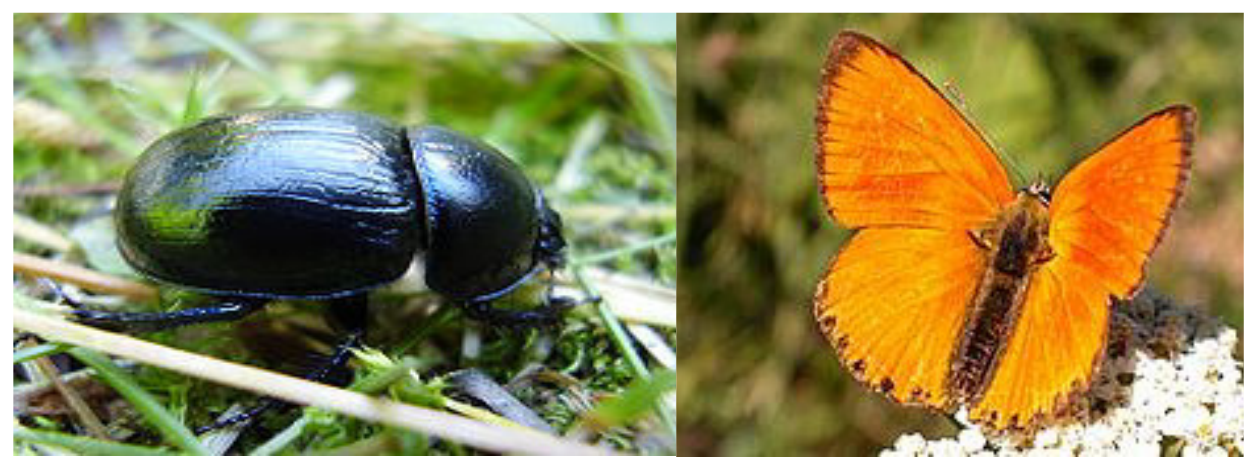

Rys.2. Żuk gnojowy [2]

Fig.2. The dung beetle [2]
Rys.3. Motyl czerwończyk (Lycaena virgaureae) - skrzydła z wyraźnymi łuskami [3]

Fig.3. Butterfly (Lycaena virgaureae) wings with clear scale coverage [3]

lot był stosunkowo wolny i głośny. $\mathrm{Z}$ tego względu stanowiły łatwy łup dla napastników co było przyczyną ich wyginięcia. Motyle ze złożoną strukturą łuskową skrzydeł pojawiły się w okresie Jurajskim. Struktury łusek skrzydeł motyli są różnorodne i bardzo złożone (Rys.3). W przypadku motyla Monarch (Danaus plexippus) $[3,4,5]$ budowa łuski jest szczególnie złożona, co powoduje, że ten gatunek jest rekordzistą zasięgu lotu: $3200 \mathrm{~km}$ w 3 tygodnie [3]. W łusce jego skrzydła można wyróżnić dwie powierzchnie oddzielone podporami tworzącymi pusta przestrzeń o grubości kilku $\mu \mathrm{m}$. Przez otwory w górnej warstwie wpływa do przestrzeni pomiędzy warstwami powietrze powodując zwiększenie siły nośnej, prędkości i sterowności lotu oraz zmniejszenie jego głośności. Dzięki temu te motyle skuteczniej mogą unikać zagrożeń, co pozwala im przetrwać. Charakterystyczną niegładką strukturę powierzchni zmniejszającą tarcie a w konsekwencji opory ruchu mają również inne zwierzęta żyjące na powierzchni gleby (np. węże) oraz w wodzie (szczególnie rekiny, tuńczyki itp.) [7,8].

\section{Praktyczne przykłady wykorzystania bioinspiracji}

Z powyższej charakterystyki jednoznacznie wynika, że proces ewolucji organizmów żywych trwający miliony lat ukierunkowany był na przystosowanie do warunków życia ich kształtu, struktury i powierzchni zewnętrznych. Maszyny i urządzenia projektowane przez inżynierów też powinny mieć kształty, struktury i powierzchnie optymalne ze względu na warunki pracy. Wiedzę w tym zakresie inżynierowie mogą uzupełnić miedzy innymi przez analizę i adaptację rozwiązań wypracowanych przez Naturę w procesie ewolucji. Poniżej przedstawione zostaną wybrane przykłady praktycznego wykorzystania inspiracji biologicznych w rozwiązywaniu wybranych problemów związanych z produkcją i wykorzystaniem energii [9-14]. 
Jednym z ekologicznych sposobów produkcji energii jest zastosowanie turbin wiatrowych. Energię wiatru przejmują łopatki turbiny i przez odpowiednie mechanizmy napędzają generator wytwarzający prąd elektryczny (Rys.4).

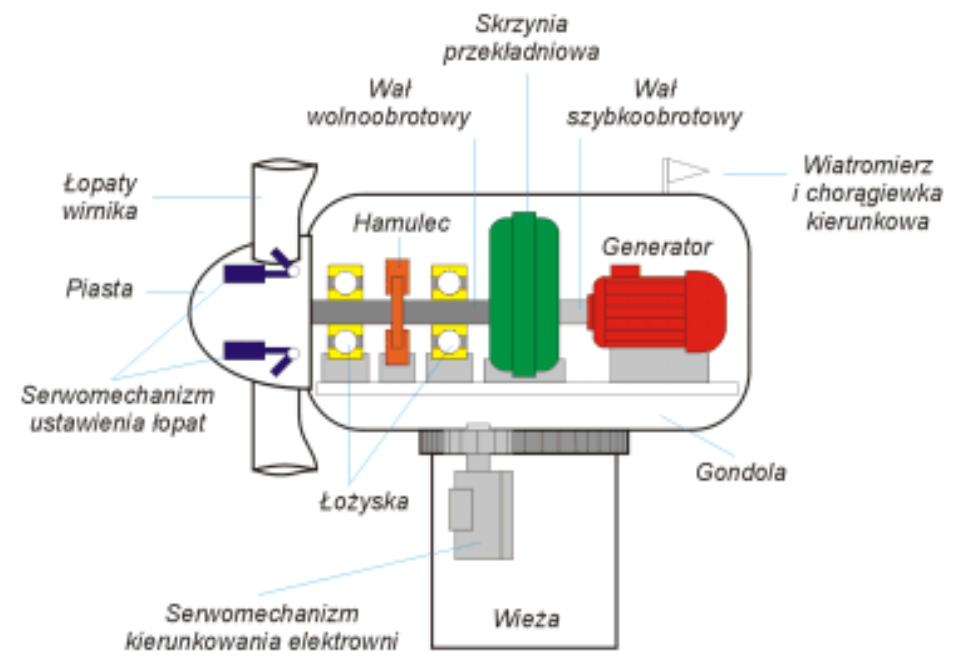

Rys.4. Uproszczony schemat budowy typowej siłowni wiatrowej [9]

Fig.4. Simplified scheme of typical wind plant [9]

Wzorując się na budowie lusek skrzydła motyla (Rys.3) opracowano bioniczną dwuwarstwową strukturę powierzchni łopatek turbiny wiatrowej o łącznej grubości ok $1 \mathrm{~mm}[3,4,5]$. W warstwie górnej z rowkami i występami laserowo wykonano otwory o powierzchni $0.16 \mathrm{~mm}^{2}$, przez które podczas pracy turbiny wpływa powietrze i wypełnia przestrzeń pomiędzy warstwami, której grubość wynosi $0.4-0.7 \mathrm{~mm}$. Badania turbiny z bionicznymi łopatkami przeprowadzono w tunelu aerodynamicznym. Wykazały one, że wykorzystanie energii kinetycznej wiatru wzrasta o $15 \% \mathrm{w}$ stosunku do turbin o klasycznej (gładkiej) powierzchni łopatek. Stwierdzono również zmniejszenie współczynnika oporu aerodynamicznego i zmniejszenie głośności pracy turbin wiatrowych $[3,4,5]$.

Zmniejszenie oporów ruchu samochodów, samolotów, pociągów czy pojazdów wodnych przekłada się na zmniejszenie zużycia paliwa czyli energii [7]. $\mathrm{W}$ tym zakresie inżynierowie wzorowali się w przypadku projektowania samolotów na budowie i locie ptaków a w przypadku statków na budowie ryb. Dwa powszechnie znane przypadki bioinspiracji to wytworzenie specjalnej folii o strukturze wzorowanej na strukturze skóry rekina i oklejanie nią kadłubów samolotów (Lufthansa) oraz zaprojektowanie przez Firmę Mercedes Bionicznego samochodu wzorowanego na rybie ,boxfish” charakteryzującej się bardzo małym oporem ruchu. W obydwu przypadkach uzyskano istotne zmniejszenie zużycie paliwa [7]. 
Zmniejszenie masy urządzeń prowadzi do zmniejszenia zużycia materiałów i oszczędności energii, którą zużyto by na ich wyprodukowanie. Wzorując się na budowie roślin w skali makro i mikro (np. pędów bambusa, trzciny, kaktusa meksykańskiego, liści drzew czy lilii wodnej) oraz ptaków i ssaków (budowa szkieletu, kształt kości i ich struktura wewnętrzna, struktura wewnętrzna dziobu dzięcioła)[9] opracowano bioniczne konstrukcje korpusów obrabiarek i elementów lotniczych. W zależności od rodzaju elementu i wzorca biologicznego bioniczne konstrukcje charakteryzowały się zwiększeniem wytrzymałości o $53-124 \%$, zwiększeniem sztywności o $21-43 \%$, zmniejszeniem masy o $3-43 \%$, zmniejszeniem odkształceń o $16-44 \%$. Bioniczne konstrukcje charakteryzowały się ponadto zwiększoną odpornością na drgania [8].

Zwiększenie trwałości elementów maszyn uzyskuje się przez zastosowanie na powierzchniach współpracujących struktury bionicznej. Badania z takimi bionicznymi powierzchniami przeprowadzono dla próbek wykonanych z szarego żeliwa odlewniczego GCI [10]. W badaniach uwzględniono kilkanaście różnych wariantów struktury bionicznej wzorowanych na strukturze powierzchni skrzydeł, tułowia i głowy żuka gnojowego (Rys.2). Porównanie próbek z powierzchniami bionicznymi z próbkami o płaskiej powierzchni wykazało, że wszystkie próbki z bioniczną strukturą posiadają większa wytrzymałość zmęczeniową. Największy wzrost wytrzymałości (o 53\%) wykazują próbki z bioniczną strukturą siatkową (kąt krzyżowania się rowków $60^{\circ}$ ). Wzrost wytrzymałości wynika przede wszystkim z: opóźnienia pojawiania się mikropęknięć oraz hamowania i zmiany kierunku propagacji. $\mathrm{W}$ analogiczny sposób istotnie poprawiono właściwości warstwy wierzchniej próbek stalowych przez zastosowanie bionicznej struktury siatkowej typu ,reseau" [10].

Zmniejszenie zużycia energii urządzeń przemysłowych, rolniczych czy budowlanych daje ogromne oszczędności energii ze względu na duża liczbę stosowanych urządzeń oraz zwykle długi czas ich pracy. Istotny wzrost efektywności pracy maszyn do uprawy ścierniska uzyskano przez zaprojektowanie tarczy tnącej wzorowanej na łapach kreta z Rys.1 [12]. Kolejnym przykładem jest bioniczna kosa (piła) do maszynowego ścinania zboża wzorowana na siekaczach świerszcza (Rys.5.), które posiadają szczególne zdolności do cięcia włókien roślinnych [13].

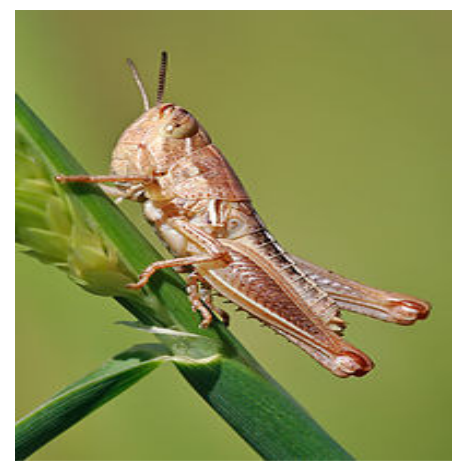

Rys.5. Świerszcz na łodydze zboża [13]

Fig.5. Grasshopper on grass stalk [13] 
Zastosowanie bionicznego rozwiązania umożliwiło zmniejszenie średniej siły ciecia (koszenia) o 28.17 \%.( z 71.88 N do 51.56 N). Równocześnie zużycie energii zmniejszyło się o $12.85 \%$. Powyższe efekty wynikają optymalnego kształtu bionicznej kosy, której ostrza były wzorowane na siekaczach świerszcza. Zęby kosy tradycyjnej były jednorodne i miały kształt pochylonego trójkąta o ostrym wierzchołku. Zęby kosy bionicznej były różnej wysokości i miały kształt wpisany w trójkąt równoramienny. Wierzchołek każdego zęba był zaokrąglony [14].

\section{Podsumowanie}

W niniejszym artykule pokazano możliwości rozwiązania problemów związanych z produkcją, oszczędnością oraz zmniejszeniem zużycia energii. Należy zwrócić uwagę, że w rozwiązaniach, które zostały wypracowane w trwającym miliony lat procesie ewolucji nie występują, w przeciwieństwie do systemów technicznych, regularne kształty, struktury i gładkie powierzchnie. Ich budowa została perfekcyjnie przystosowana do warunków życia w środowisku naturalnym. Wzorując się na kształcie łap kreta, budowie siekaczy świerszcza, strukturze zewnętrznej i wewnętrznej roślin (pędy, liście) oraz powierzchniach skrzydeł motyla, skrzydeł, tułowia i głowy żuka gnojowego, węża, rekina czy tuńczyka można poprawić efektywność produkcji energii w turbinie wiatrowej, udoskonalić narzędzia rolnicze i zmniejszyć ilość zużywanej przez nie energii, zmniejszyć tarcie i zużycie powierzchni współpracujacych elementów maszyn, zwiększyć sztywność przy jednoczesnym zmniejszeniu masy elementów lotniczych czy obrabiarkowych. Rozwój bioniki integruje środowiska naukowe i inżynierskie bo racjonalne korzystanie z rozwiązań Natury wymaga pracy zespołowej i współpracy różnych specjalistów (biolog, chemik, inżynier mechanik, inżynier energetyk, informatyk, fizyk, lekarz itp.). Bionika daje również nowe argumenty do ochrony i szacunku dla środowiska naturalnego, które jest i powinno być w coraz większym zakresie źródłem inspiracji i wiedzy wykorzystywanej dotychczas przez nasza cywilizację w niewielkim stopniu $(\sim 10 \%)$.

\section{Literatura}

[1] https://pl.wikipedia.org/wiki/Kret_europejski, \{dostęp 2016-05-22\}.

[2] https://pl.wikipedia.org/wiki/Żuk_gnojowy, \{dostęp 2016-05-22\}.

[3] https://pl.wikipedia.org/wiki/Motyle, \{dostęp 2016-05-22\}.

[4] Kovalev I., The Functional Role of the Hollow Region of the Butterfly Pyrameis atalanta (L.) Scale, Journal of Bionic Engineering 5 (2008) 224-230.

[5] Kovalev I., "Butterfly Skin' for Wind Turbines". http://bioinspired.sinet.ca, \{dostęp 2016-05-22\}.

[6] Kovalev I., "From Butterfly to Wind Turbine", Wind Engineering Vol. 34, No 4, 2010 pp. 351-360.

[7] Ruszaj A.,; Bioinspiracja w rozwiązywaniu problemów technicznych; Szkoła Naukowa Obróbek Erozyjnych - Artykuły naukowe z 2015 r., Mechanik 2015 (12) s. 255-260. 
[8] Ruszaj A., Bionic Impact on Industrial Production Development, Advances in Manufacturing Science and Technology, Vol.39, No 42015 pp. 5-22.

[9] www.elektrownie-tanio.net/schemat.html, \{dostęp 2016-05-22\}.

[10] Chen Z., Lu S., Song X., Zhang H., Yang W., Zhou H., Effects of bionic units on the fatigue wear of grey iron surface with different shapes and distributions, Optics \& Laser Technology 66 (2015) pp. 166-174.

[11] Lu J., Yang CH., Zhang L., Feng A., Jang Y., Mechanical Properties and Microstructure of Bionic Non-Smooth Stainless Steel Surface by Laser Multiple Processing, Journal of Bionic Engineering 6 (2009) pp.180-185.

[12] Li M., Chen D., Zhang S., Tong J.; "Biomimetic Design of a Stubble - Cutting Disc Using Finite Element Analysis", Journal of Bionic Engineering 10 (2013) p. 118-127.

[13] https://en.wikipedia.org/wiki/File:Young_grasshopper_on_grass_stalk02.jpg, \{dostęp 2016-05-22\}.

[14] Jia1H., Li Ch., Zhang Z., Wang G., Design of Bionic Saw Blade for Corn Stalk Cutting, Journal of Bionic Engineering 10 (2013) pp. 497-505.

\section{BIOINSPITATIONS IN ENVIRONMENTAL ENGINEERING}

\section{S u m m a r y}

Any machine tool or process design by engineers is not as excellent as alive organisms or processes occurring in natural surroundings, which have been created by the Nature in evolution process. Very intensive technology development is the reason for looking for a new and better solutions which are friendly for natural surroundings. Thanks to this fact it is possible to decrease the negative results of "greenhouse effect", ozone layer thickness decreasing in stratosphere and improve air, water and food quality. One of very important environment problem is energy production and its rational consumption. Production energy in Poland is connecting with coal, oil and natural gas burning what is harmful for natural environment. Because of this fact it is necessary to increase and develop the „clean energy" production. The very important problem is also rational energy consumption in individual households (wall isolation, kitchen equipment, radio and television) as well as in exploitation of: aircrafts, cars, agriculture machines, machines used for houses or road building, computers. Energy can be saved indirectly by decreasing machines weight and details or units wear. In this way we can save Energy which would be used for saved materials production. The bridge between solutions which can be met in alive organisms and technical application create the „bionic". The "bionic" investigates materials, structures, shapes and surfaces of plants and animals. It also investigates animals products (honeycombs, ant-hills) and specific behaviour (ants, flies, fishes). Results of this research create inspirations for construction, production, exploitation, medical or informatics tasks solving. In the paper some bionic applications in technical problems solutions in aspects of energy production and consumption are presented.

Keywords: bionic, lightweight construction, clean energy, energy efficient equipment

DOI: $10.7862 / \mathrm{rb} .2016 .220$

Przestano do redakcji: $16.05 .2016 r$.

Przyjęto do druku: $30.11 .2016 \mathrm{r}$. 